\title{
SOCIAL BEHAVIOR IN HOMOPTERA
}

\author{
By August P. Beilmann \\ Missouri Botanical Garden, St. Louis, Missouri
}

The literature relating to parental solicitude in the subsocial insects began, according to Bequært, with the writings of Herbst and Modeer in 1764. Most observations, however, have been reported during the last forty years. Bequært (1) lists but one case of parental care in the Homoptera. The following observation is of interest, since it concerns the terrapin scale (Eulecanium nigrofasciatum); hardly a promising subject for the development of social habits.

During the spring of 1932 heavy infestations of this scale were found on hawthorn and sycamore. Since dormant spraying had proven ineffective, these insects were being watched to learn the emergence date of the young. For this purpose one small undernourished hawthorn was selected, since its convenient location permitted frequent observations. On three successive mornings in June the young were seen to emerge in a body at 10 o'clock and move upward toward the new growth. When an examination toward evening failed to disclose their destination, it was assumed that these individuals were experiencing an unusual mortality rate. However, more young made their appearance the following morning, and continued to move about during the sunny hours. About 4 o'clock very few could be found, although some had settled on the foliage. It was then observed that a few stragglers were returning to the adult scales and after slight hesitation were crawling underneath. Again on the third morning, the nymphs appeared at one time and began their journey up the branch toward the new growth. Observations were more frequent during the afternoon and an additional number were found permanently located on the leaves. However, about $3: 30 \mathrm{P}$. M. the general movement of the larvæ was reversed. They began to come down the branch-for some of them a journey of three feetand to disappear beneath the adult females. Within twenty 
minutes all had returned to remain safely covered for the night.

Simanton (2) has published a very comprehensive account of this scale as it occurs on the peach in Pennsylvania. He has noted the well timed emergence in the morning, but does not mention having seen any evidence of a return in the evening. This performance may have been due solely to the de-vitalized condition of the tree upon which the observations were made. The total new twig growth did not exceed two inches per year, and hardly more than four scrawny leaves grew from each branch tip. Thus, suitable locations for feeding and growth were reduced to a minimum. The apparently aimless wanderings and the return during the night, may have been due solely to the restricted choice of feeding sites.

\section{LITERATURE CITED}

1. Bequaert, J., 1935. Presocial behavior among the Hemiptera. Bull. Brooklyn Ent. Soc. XXX, pp. 177-191.

Book REviEw. - A Monograph of the British Neuroptera, Vol. I, by Frederick J. Killington. Pp. 1-269, 68 text-figures and 15 plates. Printed for the Ray Society and sold by Bernard Quaritch, Ltd., London. This is the first comprehensive account of the British Neuroptera since MacLachlan's "Monograph" in 1868. The book is divided into six chapters. The first deals with the morphology of the families of British Neuroptera with special reference to the genitalia; the second, third, and fourth are concerned with the metamorphosis of the British species; the fifth deals with the bionomics; and the sixth with the systematics of the Coniopterygidæ, Osmylidæ, Sisyridæ and a few genera of Hemerobiidæ. The second volume will apparently consist of a systematic account of the rest of the Hemerobiidæ and the Chrysopidæ, as well as the entire bibliography. Although the systematic part of this book is of interest only to the specialist in the Neuroptera, the first five chapters should be of general interest to entomologists, since they contain much new information on the structure and biology of these insects.

F. M. CARPENTER. 

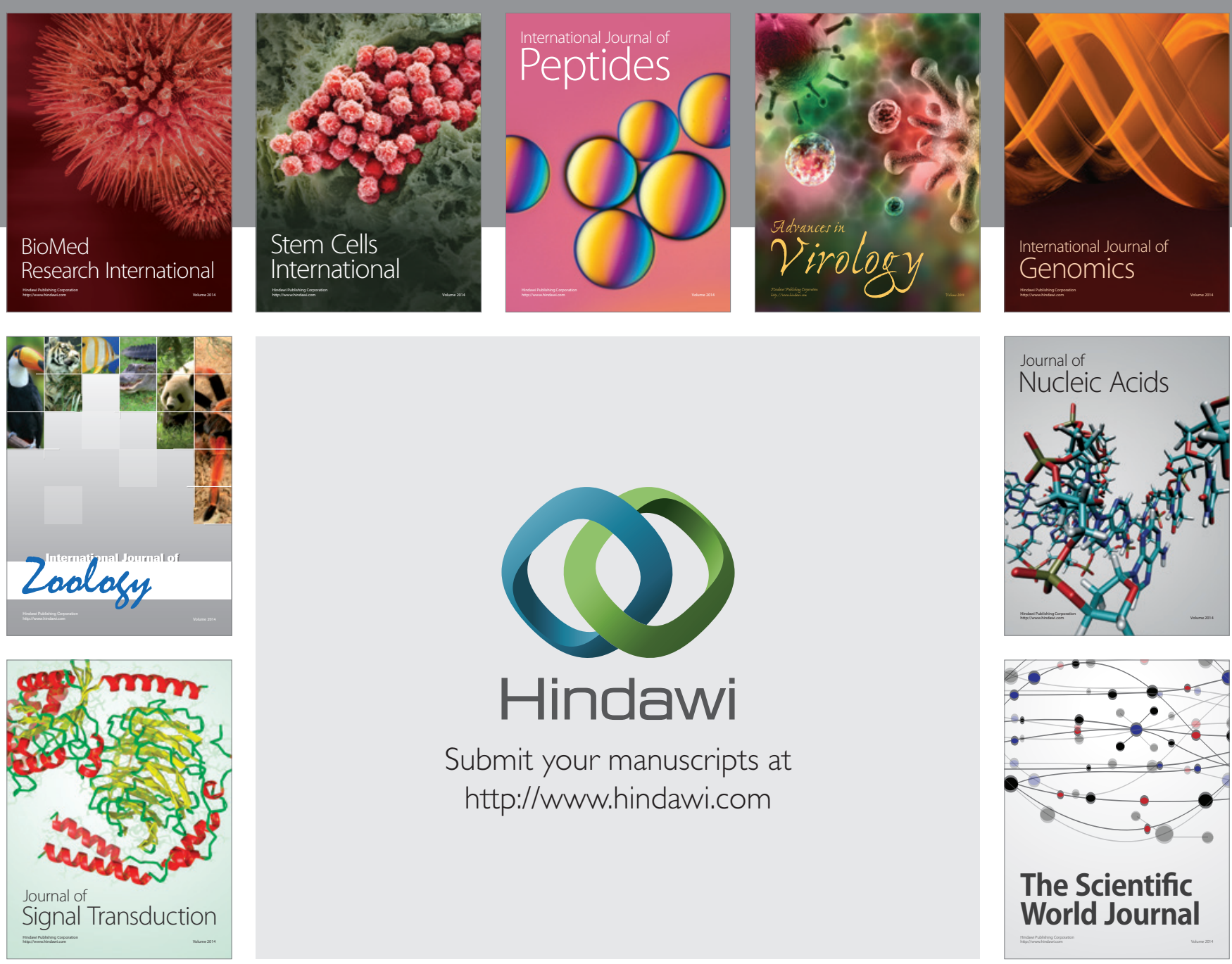

Submit your manuscripts at

http://www.hindawi.com
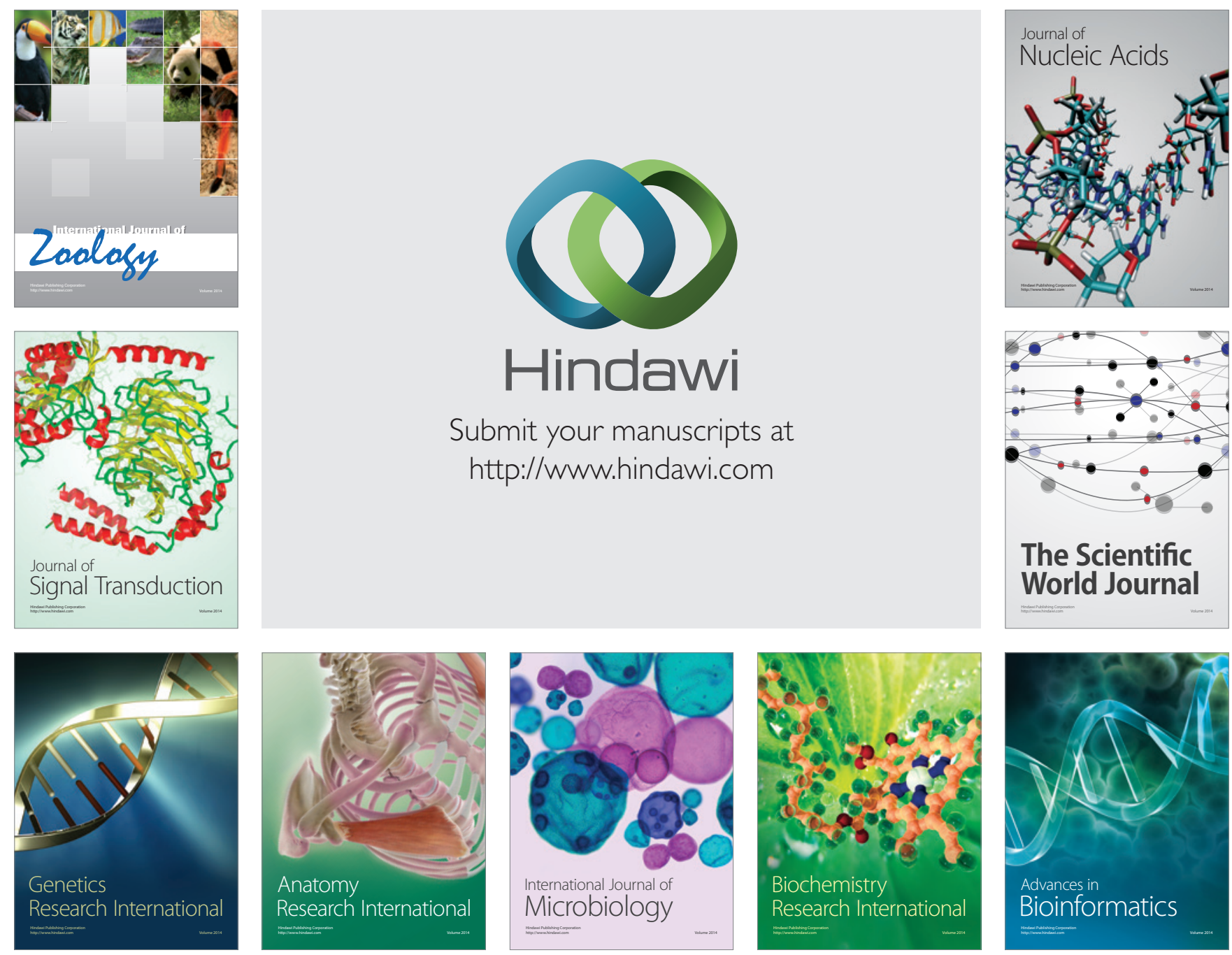

The Scientific World Journal
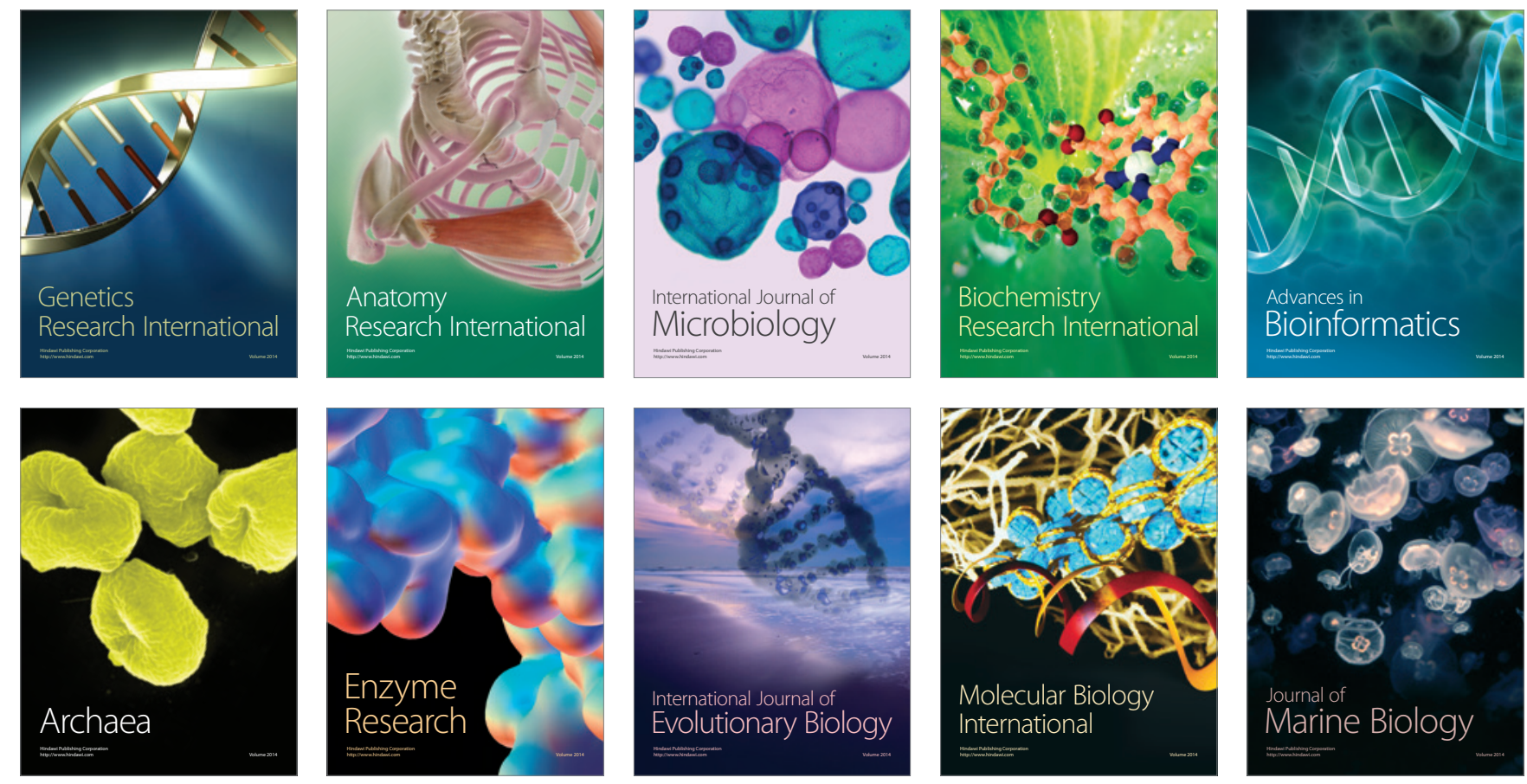